\title{
Nilai Prediktif MRI Kardiak Pasca STEMI Peran Late Enhancement
}

\author{
Irnizarifka, Wicaksono S.H., Kuncoro A.S., Kasim M.
}

$\mathrm{F}$ orum Pencitraan Kardiovaskular edisi sebelumnya membahas tentang peran Magnetic Resonancec Imaging (MRI) kardiak pada kasus Penyakit Jantung Koroner dalam kondisi akut maupun kronik. Dalam forum kali ini, kami sajikan contoh kasus penggunaan MRI kardiak pada pasien pasca Infark Miokard Akut Elevasi ST (IMAEST) yang dilakukan pemeriksaan MRI kardiak saat perawatan sebagai stratifikasi risiko pasien pasca IMAEST.

Penyakit kardiovaskular masih menjadi penyebab morbiditas dan mortalitas tertinggi di dunia, dengan penyakit arteri koroner (PAK) sebagai manifestasi utamanya. ${ }^{1}$ Dengan semakin berkembangnya manajemen serangan jantung akut, setidaknya $70 \%$ pasien yang dirawat di rumah sakit dengan infark miokard akut (IMA) berhasil melewati fase akutnya. Namun, konsekuensi jangka panjang pasca serangan akut tetap dapat terjadi meskipun intervensi fase akut telah dilakukan. Dengan demikian, ketepatan waktu dalam mendiagnosis IMAEST menjadi sangat penting. 2,3

Serangan IMAEST memiliki berbagai variasi dampak pada harapan hidup jangka panjang. Pasca IMAEST, seseorang yang mengalami gagal jantung memiliki prognosis yang lebih buruk. Dengan demikian, penilaian prediktif terhadap morbiditas

Alamat korespondensi:

dr. Sony H Wicaksono, SpJP. Departemen Kardiologi dan Kedokteran Vaskular FKUI dan Pusat Jantung Nasional Harapan Kita, Jakarta. E-mail: dr.sonyhw@yahoo.com dan mortalitas yang dilakukan saat terjadi IMAEST memiliki peranan menguntungkan, sehingga terapi preventif dapat mulai diterapkan di saat yang tepat. ${ }^{4,}$ 5 Di antara modalitas pencitraan yang ada, MRI kardiak dengan kontras dengan stress adenosin, menjadi salah satu pilihan untuk stratifikasi risiko pasca IMAEST. ${ }^{6}$

\section{Ilustrasi Kasus}

Dilaporkan seorang laki-laki berusia 53 tahun dirujuk ke UGD Harapan Kita dengan nyeri dada khas infark sejak 11 jam sebelum masuk rumah sakit. Pasien tersebut didiagnosis sebagai STEMI inferior akut namun belum mendapatkan terapi revaskularisasi di rumah sakit sebelumnya. Saat tiba di UGD harapan Kita, elevasi segmen ST pada rekaman EKG sudah tidak terlihat lagi, namun enzim jantung meningkat. Diagnosis kemudian ditegakkan dengan STEMI inferior akut dengan autolysis.

Di hari perawatan ke-2, pasien menjalani koroangiografi dengan hasil CAD 1 VD (total oklusi di LCx). Stress Adenosin MRI kardiak dengan kontras dilakukan 3 hari setelahnya untuk menentukan iskemik residual di lesi culprit, iskemik di area koroner lain bila ada, luas infark, serta mendeteksi keberadaan obstruksi mikrovaskular dan edema miokard di sekitar area nekrosis sebagai area terancam infark atau area at risk (AAR).

Disfungsi ventrikel kiri pasca IMAEST dapat diakibatkan oleh nekrosis, myocardial stunning atau 

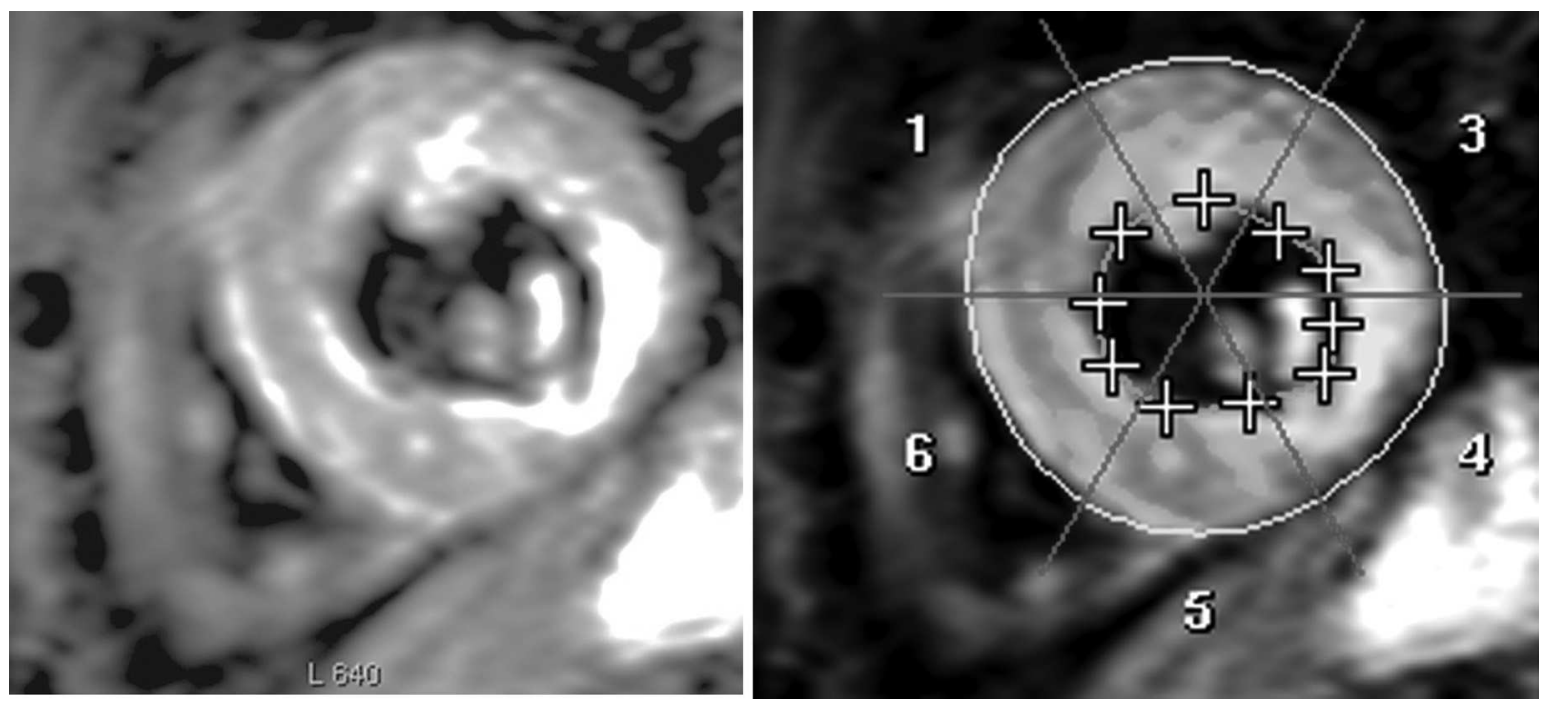

Gambar 1. Edema miokard terutama pada dinding midinferolateral setelah dilakukan pengukuran luas edema (area berwarna kemerahan).

hibernasi, bahkan ketiganya secara bersamaan. ${ }^{6}$ Pada pemeriksaan MRI kardiak, terlihat fungsi sistolik kedua ventrikel normal, namun terdapat hipokinetik ringan pada dindng miokard inferior. Melalui sekuens T2WSTIR tanpa kontras, edema miokard pada fase akut IMA dapat terlihat sebagai sebuah gambaran terang pada area miokard. Gambaran ini disebut dengan area at risk (AAR). Pada kasus ini, edema miokard terlihat terutama di segmen midinferoseptal dan dengan luas
38\% (Gambar 1). Sementara pada sekuens stress adenosin terlihat iskemia pada segmen midanteroseptal (area LAD) dan segmen midinferolateral (area LCx) (Gambar 2).

Sekuens Late Gadolinium Enhancement (LGE) pada Gambar 3 memperlihatkan suatu nekrosis pada dinding midinferolateral dengan transmuralitas $70 \%$ dan volume nekrotik (infarctsize - IS) sebesar 20\%. Dengan demikian, hasil perhitungan miokard yang dapat diselamatkan atau

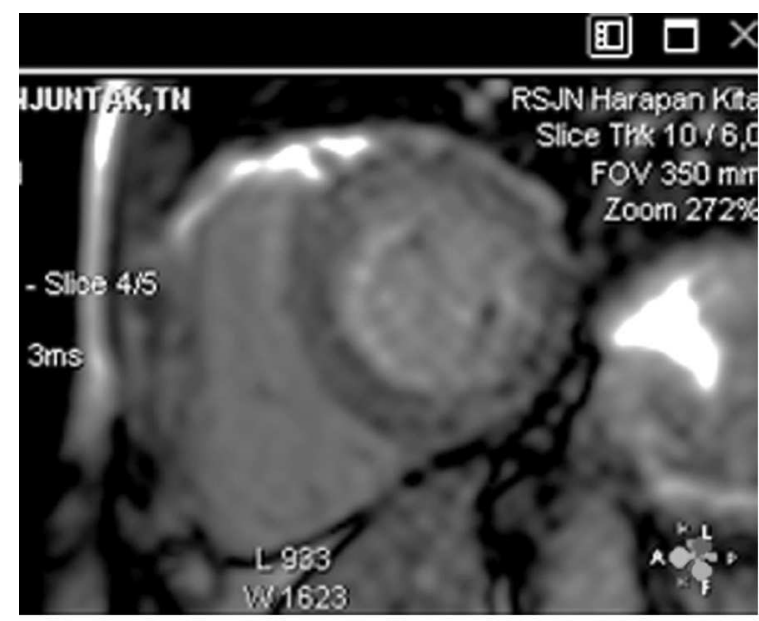

Rest

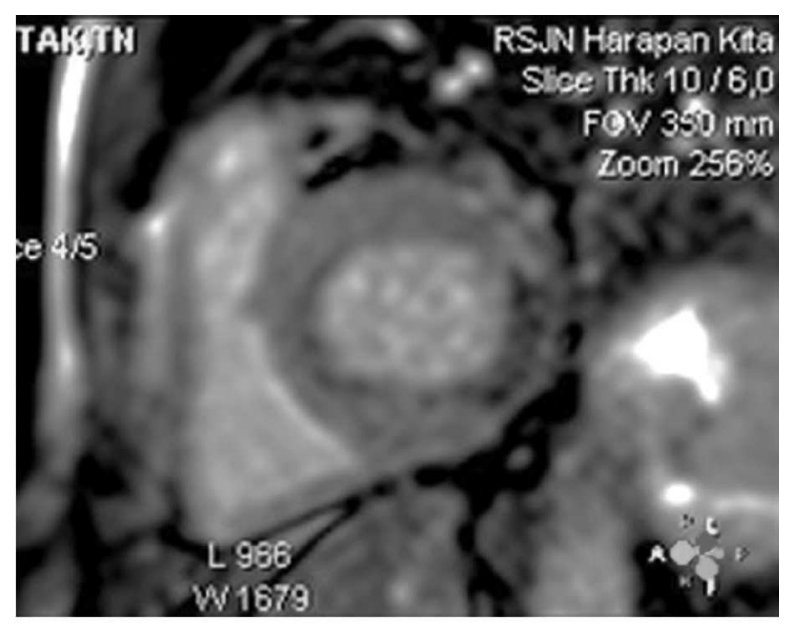

Stress

Gambar 2. Tampak iskemia saat stress yang tidak tampak saat rest di area LCx dan area LAD. 


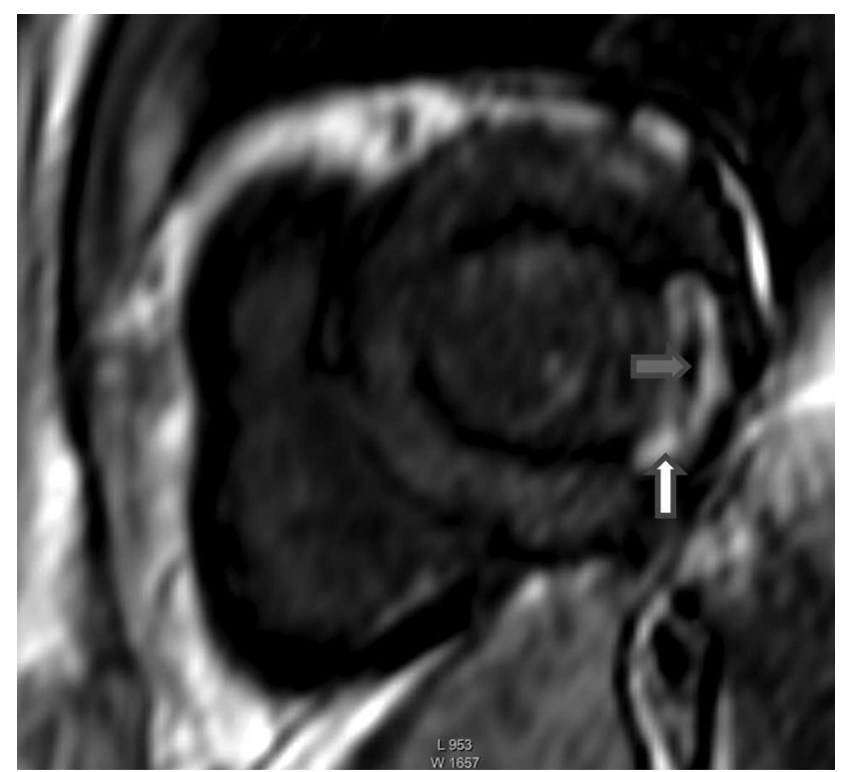

Gambar 3. Terlihat nekrosis (warna putih ditunjuk panah putih) dan Late MVO (warna hitam ditunjuk panah biru) pada pemeriksaan LGE

salvageable myocardium (SM) yang didapatkan sebesar $18 \%$ (47\% dari seluruh AAR). Pada pemeriksaan yang sama juga dapat dilihat late MVO (gambaran hypoenhancement).

\section{Diskusi}

MRI kardiak dapat mendeteksi secara in vivo konsekuensi dari IMAEST baik berupa data luas infark (IS), area at risk (AAR), iskemik residu, viabilitas miokard dan MVO. Pemeriksaan MRI pada kasus ini digunakan untuk melihat iskemik residu pada lesi culprit, inducible ischemia pada lesi non culprit, ukuran infark, dan late $M V O$.

Sebuah penelitian oleh Larose dkk di tahun 2010 mendapatkan hasil bahwa volume LGE di fase awal STEMI dapat memprediksi komplikasi gagal jantung dan komplikasi lain melebihi faktor risiko tradisional lain seperti luas infark, kenaikan maksimal CKMB, munculnya gelombang $\mathrm{Q}$, dan fraksi ejeksi saat IMAEST. ${ }^{4}$ Luas infark melalui pemeriksaan MRI kardiak dalam 1 minggu dari IMA memiliki korelasi yang lebih kuat terhadap komplikasi setelahnya bila dibandingkan dengan pengukuran fraksi ejeksi ventrikel kiri. Kejadian disfungsi ventrikel kiri dalam 6 bulan pertama diketahui meningkat bila didapatkan luas LGE $\geq 23 \%$ serta perbaikan fungsional akan lebih baik bila didapat transmuralitas $<75 \%$. ${ }^{7}$ Pada kasus ini, nekrosis yang terjadi memiliki transmuralitas $70 \%$ dan luas infark 20\%, sehingga disimpulkan kemungkinan yang cenderung menuju kejadian disfungsi ventrikel
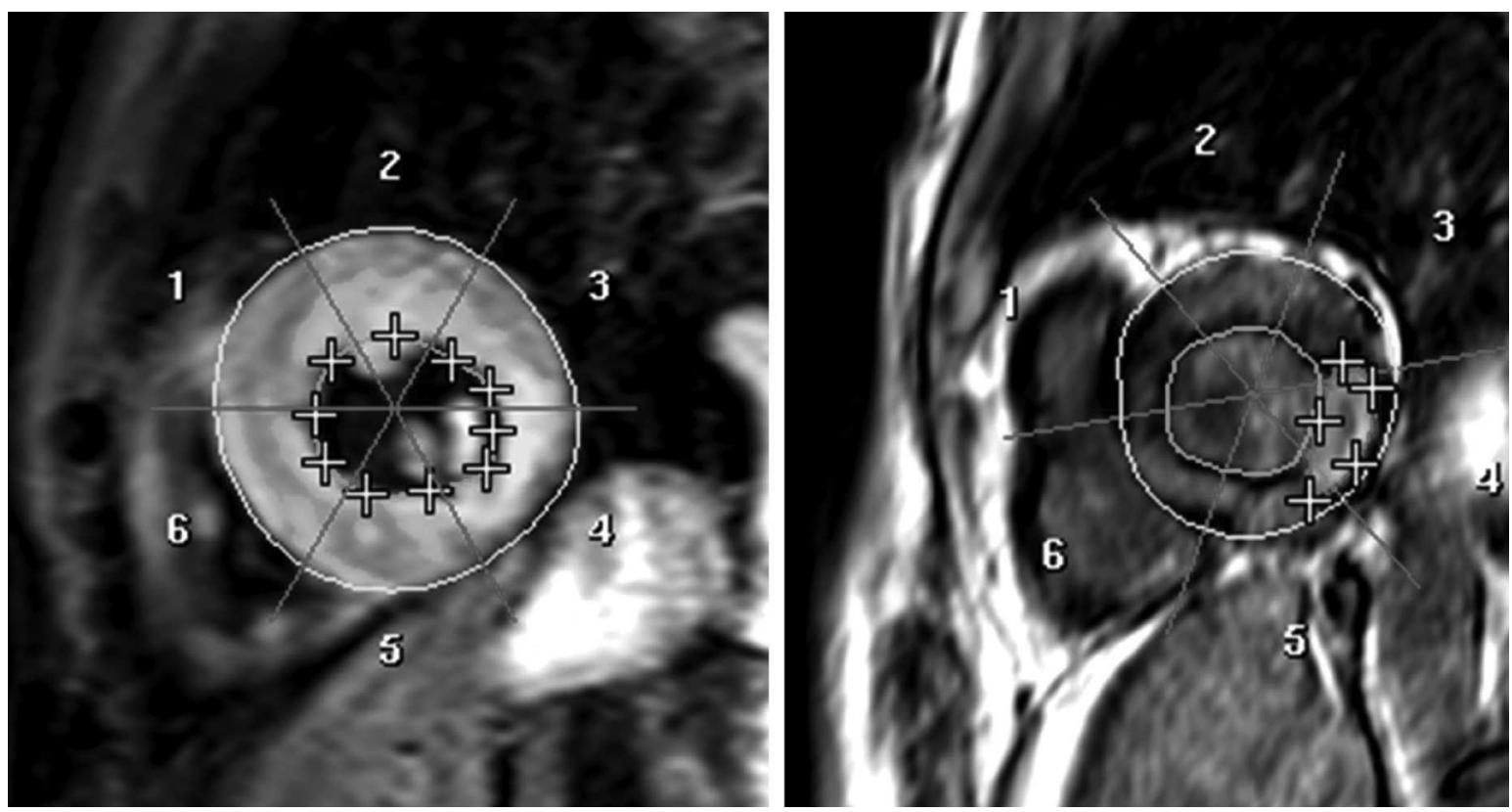

Gambar 3. Perbandingan Luas Area At Risk (AAR) dengan luas area infark atau infarct size (IS) 

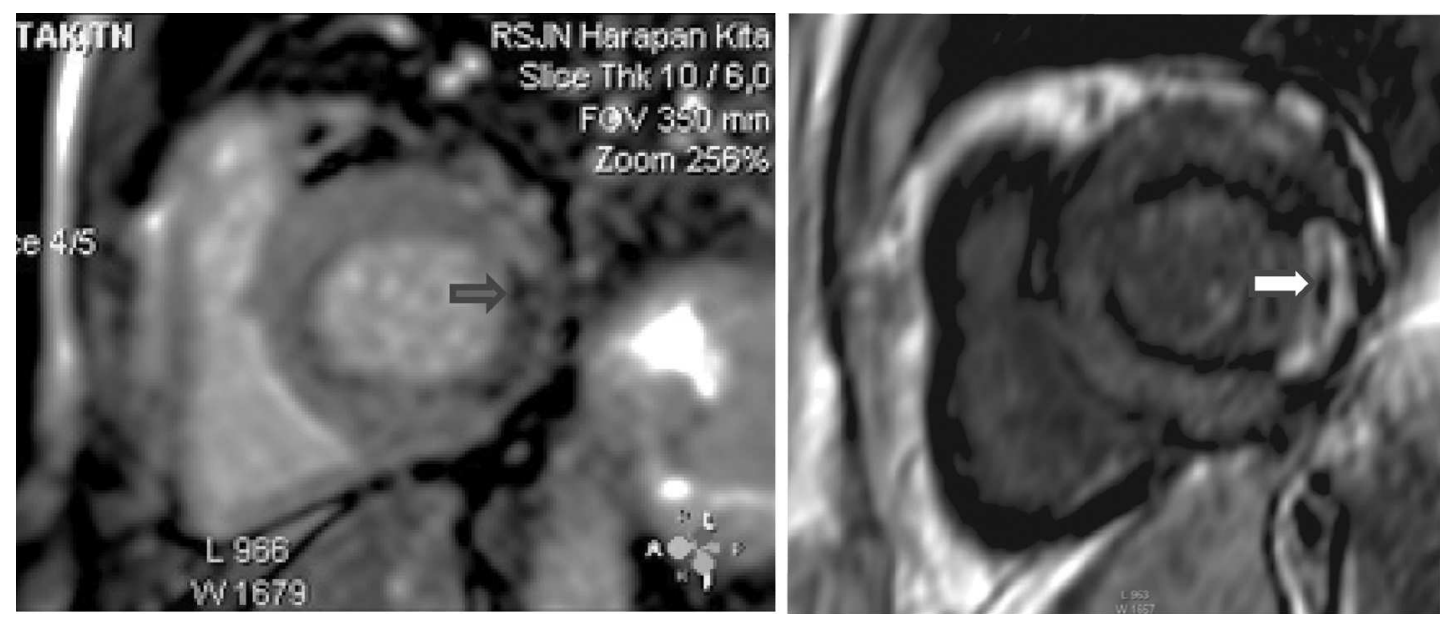

Gambar 4. Perbandingan area stress inducible ischemia dengan area infark

kiri, dengan kemungkinan perbaikan fungsional yang juga kecil.

\section{Daftar Pustaka}

1. Hamm CW, Bassand JP, Agewall S, et al. ESC Guidelines for the management of acute coronary syndromes in patients presenting without persistent ST-segment elevation: The Task Force for the management of acute coronary syndromes (ACS) in patients presenting without persistent ST-segment elevation of the European Society of Cardiology (ESC). European heart journal 2011; 32(23): 2999-3054.

2. Taylor J. 2012 ESC Guidelines on acute myocardial infarction (STEMI). European heart journal 2012; 33(20): 2501-2.

3. Daga LC, Kaul U, Mansoor A. Approach to STEMI and NSTEMI. The Journal of the Association of Physicians of India 2011; 59 Suppl: 19-25.

4. Larose E, Rodes-Cabau J, Pibarot P, et al. Predicting late myocardial recovery and outcomes in the early hours of ST-segment elevation myocardial infarction traditional measures compared with microvascular obstruction, salvaged myocardium, and necrosis characteristics by cardiovascular magnetic resonance. Journal of the American College of Cardiology 2010; 55(22): 2459-69.

5. Berman DS, Hachamovitch R, Shaw LJ, et al. Roles of nuclear cardiology, cardiac computed tomography, and cardiac magnetic resonance: Noninvasive risk stratification and a conceptual framework for the selection of noninvasive imaging tests in patients with known or suspected coronary artery disease. Journal of nuclear medicine : official publication, Society of Nuclear Medicine 2006; 47(7): 1107-18.

6. Van de Werf F, Bax J, Betriu A, et al. Management of acute myocardial infarction in patients presenting with persistent ST-segment elevation: the Task Force on the Management of ST-Segment Elevation Acute Myocardial Infarction of the European Society of Cardiology. European heart journal 2008; 29(23): 2909-45.

7. Perazzolo Marra M, Lima JA, Iliceto S. MRI in acute myocardial infarction. European heart journal 2011; 32(3): 284-93. 